\title{
GMR
}

\section{Genetic and epigenetic alterations induced by different levels of rye genome integration in wheat recipient}

X.L. Zheng*, J.P. Zhou*, L.L. Zang, A.T. Tang, D.Q. Liu, K.J. Deng and Y. Zhang

School of Life Sciences and Technology, University of Electronic Science and Technology of China, Chendu, Sichuan, China

*These authors contributed equally to this study.

Corresponding author: Y. Zhang

E-mail: zhangyong916@uestc.edu.cn

Genet. Mol. Res. 15 (2): gmr.15028001

Received November 5, 2015

Accepted January 15, 2016

Published June 17, 2016

DOI http://dx.doi.org/10.4238/gmr.15028001

ABSTRACT. The narrow genetic variation present in common wheat (Triticum aestivum) varieties has greatly restricted the improvement of crop yield in modern breeding systems. Alien addition lines have proven to be an effective means to broaden the genetic diversity of common wheat. Wheat-rye addition lines, which are the direct bridge materials for wheat improvement, have been wildly used to produce new wheat cultivars carrying alien rye germplasm. In this study, we investigated the genetic and epigenetic alterations in two sets of wheatrye disomic addition lines (1R-7R) and the corresponding triticales. We used expressed sequence tag-simple sequence repeat, amplified fragment length polymorphism, and methylation-sensitive amplification polymorphism analyses to analyze the effects of the introduction of alien chromosomes (either the entire genome or sub-genome) to wheat genetic background. We found obvious and diversiform variations in the genomic primary structure, as well as alterations in the extent and 
pattern of the genomic DNA methylation of the recipient. Meanwhile, these results also showed that introduction of different rye chromosomes could induce different genetic and epigenetic alterations in its recipient, and the genetic background of the parents is an important factor for genomic and epigenetic variation induced by alien chromosome addition.

Key words: Wheat-rye addition lines; Genetic alterations; Epigenetic alterations

\section{INTRODUCTION}

The narrow genetic background of wheat (Triticum aestivum) is one of the main factors limiting increases in wheat yield. The introduction of an alien genetic germplasm is a common method for genetic improvement of wheat. Many wild relatives with important agronomic traits, such as rye (Secale cereale L.), Haynaldia villosa, and Elytrigia elongata, are ideal materials for use in wheat genetic breeding (Qi et al., 2007; Gill et al., 2011; Kang et al., 2011; Liu et al., 2011; Jauhar and Peterson, 2013; Zhou et al., 2014). Rye is a valuable source of resistance, stress tolerance, and high yield genes, and it has been extensively used for yield improvement, disease resistance, and environmental adaptation of common wheat (Friebe et al., 1996; Tang et al., 2009; Ren et al., 2011).

Triticale was obtained by introgression of rye chromatin into the wheat genome, and is often used to produce wheat-rye addition, substitution, and translocation lines. Moreover, alien addition lines have been used to induce small-segment-translocation between species effectively (Ren and Zhang, 1997; Tan, 2008). In wheat, it has been reported that wheat-rye monosomic addition lines can easily induce structural variation in the chromosome and a high frequency of chromosome translocation (Ren et al., 1990; Ren and Zhang, 1997). In rice (Oryza sativa L.), some useful genes were transferred to cultivated rice from its wild relatives, using alien addition lines (Brar and Khush, 1997; Multani et al., 2003). Alien addition lines were also used in breeding programs of sugar beet, oilseed rape, wheat, and onion (Reamon-Ramos and Wricke, 1992; Chevre et al., 1996; Ren and Zhang, 1997; van Heusden et al., 2000).

Polyploidization-induced genome variation has been investigated in triticale (Ma et al., 2004; Ma and Gustafson, 2006). The alterations of rye telomeric/subtelomeric heterochromatin have been observed in several sets of wheat-rye addition lines (Alkhimova et al., 1999). Chromosome instability and genome rearrangements in wheat-rye addition lines have also been observed (Bento et al., 2010; Szakács and Molnár-Láng, 2010). Drastic genetic and epigenetic variations were induced by wheat-rye $2 \mathrm{R}$ and $5 \mathrm{R}$ monosomic addition lines (Fu et al., 2013).

Although many alien addition lines have been used in crop breeding, there are two important questions that remain unclear. First, whether and how whole genomes and different sub-genomes induce different impacts on genetic and epigenetic alterations in the recipient plant. Second, whether the genetic background of the recipient parents has an impact on the changes induced by the alien addition. To address these issues, we investigated genetic variation in genomic structure and alterations in the extent and pattern of DNA methylation in two sets of wheat-rye disomic addition lines (1R-7R) and the corresponding triticales. Our results provide more detailed and comprehensive information about wheat-rye disomic addition lines, which might constitute a theoretical basis for further fundamental research and breeding application. 


\section{MATERIAL AND METHODS}

\section{Plant material}

The plant material used in this study consisted of two sets of wheat-rye disomic addition lines, triticales, and their agronomic parents. CS-I: T. aestivum "Chinese Spring" $\times$ S. cereale "Imperial" $(2 \mathrm{n}=8 \mathrm{x}, \mathrm{AABBDDRR}), T$. aestivum "Chinese Spring" (AABBDD), S. cereale "Imperial" (RR), and a set of wheat-rye addition lines (1R-7R); H-K: T. aestivum "Holdfast" $\times$ S. cereale "King II" $(2 \mathrm{n}=8 \mathrm{x}$, AABBDDRR), T. aestivum "Holdfast" (AABBDD), $S$. cereale "King II" (RR), and a set of wheat-rye addition lines (1R-7R). All these materials were provided by Professor J. Perry Gustafson at the University of Missouri (Ma et al., 2004).

\section{Expressed sequence tag-simple sequence repeat (EST-SSR) analysis}

In total, 69 primer pairs were selected and analyzed in this study. Polymerase chain reaction (PCR) was done in a total volume of $20 \mu \mathrm{L}$, containing $50 \mathrm{ng}$ genomic DNA, $0.5 \mathrm{U}$ Taq DNA polymerase, and $1 \mathrm{X}$ buffer (Promega, Madison, WI, USA) consisting of $1.5 \mathrm{mM}$ $\mathrm{MgCl}_{2}, 0.2 \mathrm{mM} \mathrm{dNTP}$, and $0.25 \mathrm{mM}$ of each primer. The following program was used: $94^{\circ} \mathrm{C}$ for $5 \mathrm{~min}, 30$ cycles of $94^{\circ} \mathrm{C}$ for $30 \mathrm{~s}, 56^{\circ} \mathrm{C}$ for $30 \mathrm{~s}$, and $72^{\circ} \mathrm{C}$ for $1 \mathrm{~min}$, followed by a final extension at $72^{\circ} \mathrm{C}$ for $10 \mathrm{~min}$. Polymorphism was visualized on a silver-stained $8 \%$ native polyacrylamide gel.

\section{Amplified fragment length polymorphism (AFLP) and methylation-sensitive amplification polymorphism (MSAP) analysis}

The AFLP procedure was performed according to the protocol of Vos et al. (1995), with minor modifications (Zhang et al., 2008). The MSAP procedure followed that described by Zhang et al. (2008). The preselected PCR amplification was performed using a single

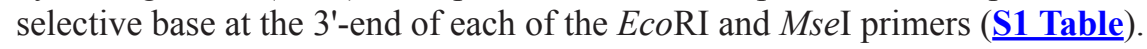

\section{Scoring of polymorphic bands}

In all EST-SSR, AFLP, and MSAP procedures, replicates were performed to avoid technical bias, and the patterns from two independent digestions were compared for each sample. Moreover, with all EST-SSR, AFLP, and MSAP gels, the upper and the lower part of the gel, where the resolution was not satisfactory, were not used for band scoring. Only stable and repeatable patterns were retained for subsequent analysis.

\section{Isolation and analysis of polymorphic fragments}

The polymorphic fragments were isolated from the polyacrylamide gels, re-amplified by PCR, and sequenced. The polymorphic bands were excised from the PAGE, and boiled in $100 \mu \mathrm{L}$ water to release the DNA. The eluted DNA was used as template for the PCR following the same cycling conditions as the selective amplification. The PCR products were subsequently separated on a $2 \%$ agarose gel, and DNA fragments of the appropriate size were 
extracted from the gel using the Sangon PCR Purification Kit (Sangon, Shanghai, China). The target bands were ligated to the pMD18 T-vector (TaKaRa, Dalian, Japan) and transferred to Escherichia coli strain JM109 competent cells by heat shock. The positive clones were sequenced using universal M13 primers and the nucleotide sequences were deposited in the GenBank database. Sequences obtained in this study were analyzed for similarity to known sequences in public databases using BLAST on the National Center for Biotechnology Information server (http://www.ncbi.nlm.nih.gov/BLAST/).

\section{RESULTS}

\section{Analysis of addition-associated genetic alterations}

The 69 selective primer pairs were used for EST-SSR analysis to test the polymorphism among the genomes of a set of wheat-rye addition lines, their corresponding triticale, and agronomic parents. As shown in Figure 1, a total of 353 legible and reproducible bands were generated in CS-I. Among the 353 amplified fragments, 227 (64.3\%), 91 (25.8\%), 218 (61.8\%), 201 (56.9\%), 228 (64.6\%), 242 (68.6\%), 231 (65.4\%), 221 (62.6\%), $127(36.0 \%)$, and $204(57.8 \%)$ amplified sites, respectively, were detected in the wheat parent (W), rye parent $(\mathrm{R})$, triticale (WR), and wheat-rye addition lines (1R-7R). In the comparison of the amplified fingerprints between the addition lines and wheat parents, 250 polymorphic fragments were generated in the wheat-rye addition lines, which comprised $75.30 \%$ of the detected EST-SSR sites. Among the polymorphic sites, the number of lost and novel sites was $145(43.67 \%)$ and $105(31.63 \%)$, respectively. This result indicated that the frequency of lost parental bands was much higher than the frequency of gained novel bands, due to the introduction of rye germplasms. Further analysis of the polymorphic types in the 1R-7R addition lines are shown in Table 1. Our analysis suggested that the genome alteration observed in triticale was similar to that which occurred in the wheat-rye addition lines, in which the frequency of lost and novel sites was 16 and $9 \%$.

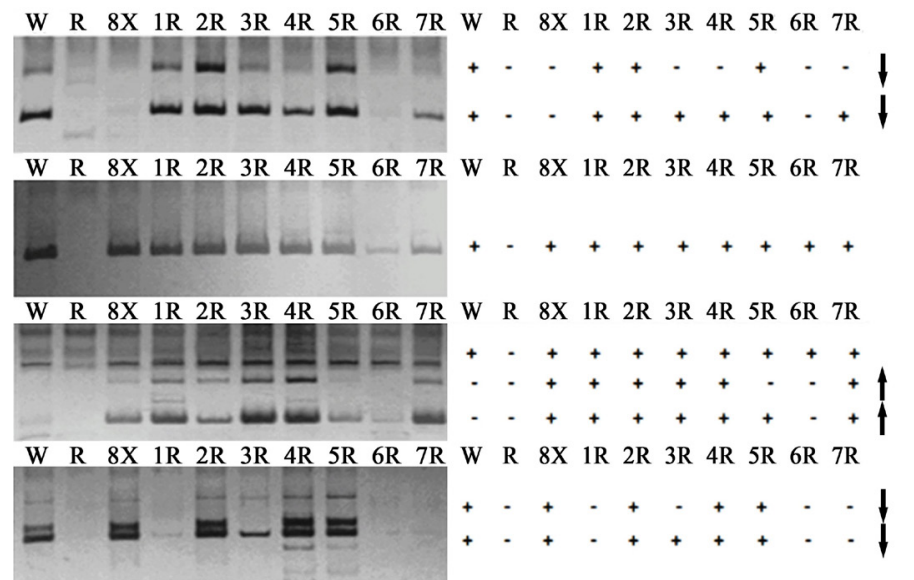

Figure 1. EST-SSR fingerprints of genomic DNA of wheat-rye additional lines and their parents. $\mathrm{W}=$ wheat parent $(\mathrm{AABBDD}) ; \mathrm{R}=$ rye parent $(\mathrm{RR}) ; 8 \mathrm{X}=$ triticale $(2 \mathrm{n}=8 \mathrm{x}, \mathrm{AABBDDRR}) ; 1 \mathrm{R}-7 \mathrm{R}$ : wheat-rye addition lines. $(+=$ band present, - = band absent; $\uparrow=$ appearance of novel bands, $\downarrow=$ band loss). 
Table 1. Polymorphic amplified sites obtained using EST-SSR.

\begin{tabular}{|c|c|c|c|c|c|c|c|c|c|c|c|c|c|c|c|c|c|c|}
\hline & & & & & & $\bar{R}$ & & $\mathrm{R}$ & & $\bar{R}$ & & $\mathrm{R}$ & & & & $\mathrm{s}$ & & $\mathrm{R}$ \\
\hline \multirow{6}{*}{ Lost } & $\mathrm{W}^{*}$ & $\mathrm{R}^{*}$ & $\mathrm{~T}^{*}$ & $\mathrm{AL}^{*}$ & No. & $\%$ & No. & $\%$ & No. & $\%$ & No. & $\%$ & No. & $\%$ & No. & $\%$ & No. & $\%$ \\
\hline & + & - & + & - & 20 & 5.67 & 8 & 2.27 & 17 & 4.82 & 13 & 3.68 & 21 & 5.95 & 70 & 19.8 & 22 & 6.23 \\
\hline & + & - & - & - & 25 & 7.08 & 28 & 7.93 & 16 & 4.53 & 20 & 5.67 & 24 & 6.8 & 32 & 9.07 & 20 & 5.67 \\
\hline & + & + & + & - & 3 & 0.85 & 4 & 1.13 & 3 & 0.85 & 6 & 1.70 & 9 & 2.55 & 13 & 3.68 & 4 & 1.13 \\
\hline & + & + & - & - & 1 & 0.28 & 1 & 0.28 & 1 & 0.28 & 1 & 0.28 & 0.00 & 0.00 & 1 & 0.28 & 1 & 0.28 \\
\hline & \multicolumn{4}{|c|}{ TotaL } & 49 & 13.88 & 41 & 11.61 & 37 & 10.48 & 40 & 11.33 & 54 & 15.30 & 116 & 32.83 & 47 & 13.31 \\
\hline \multirow{3}{*}{ Novel } & - & - & + & + & 10 & 2.93 & 13 & 3.68 & 12 & 3.40 & 10 & 2.83 & 11 & 3.12 & 3 & 0.85 & 10 & 2.83 \\
\hline & - & - & - & + & 9 & 2.55 & 24 & 6.8 & 29 & 8.22 & 25 & 7.08 & 21 & 5.95 & 6 & 1.7 & 10 & 2.83 \\
\hline & \multicolumn{4}{|c|}{ 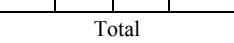 } & 19 & 5.48 & 37 & 10.48 & 41 & 11.62 & 35 & 9.91 & 32 & 9.07 & 9 & 2.55 & 20 & 5.66 \\
\hline
\end{tabular}

$* \mathrm{~W}=$ wheat $\mathrm{R}=$ rye; $\mathrm{T}=$ triticale; $\mathrm{AL}=$ addition lines; $1 \mathrm{R}-7 \mathrm{R}=1 \mathrm{R}-7 \mathrm{R}$ addition lines; $+=$ band present; $-=$ band absent.

Using eight selective primer pairs in the AFLP analysis, 398 and 372 polymorphic bands were obtained in CS-I and H-K, respectively, with the exception of bands produced by the rye parent (Figure 2). In CS-I, compared to the wheat parent, 67 (16.83\%) sites were absent, while $41(10.30 \%)$ new bands were observed in the addition lines. Further analysis of the 1R-

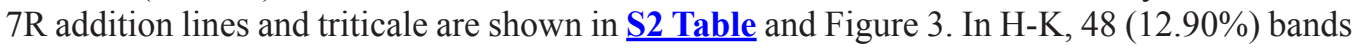
disappeared and $28(7.53 \%)$ new bands appeared in the addition lines compared to the wheat parent (S2 Table and Figure 3). These results indicated an extensive occurrence of band loss and gain in wheat-rye addition lines and triticale. Meanwhile, the frequency of lost parental bands was much higher than the frequency of novel band gain. Further analysis revealed that the average rate of band loss in CS-I (12.02\%) was twice that found in H-K (5.99\%). Furthermore, the average rate of gain of new bands in CS-I (6.71\%) was approximately three times the rate observed in H-K (2.34\%). Our analyses also revealed a high similarity of alternation patterns between the addition lines and corresponding triticale. Taken together, our results suggest that the addition of alien germplasm, either the entire genome or sub-genome, would evoke obvious and extensive variations in genomic primary structure of the wheat recipient, such as sequence deletion and insertion.

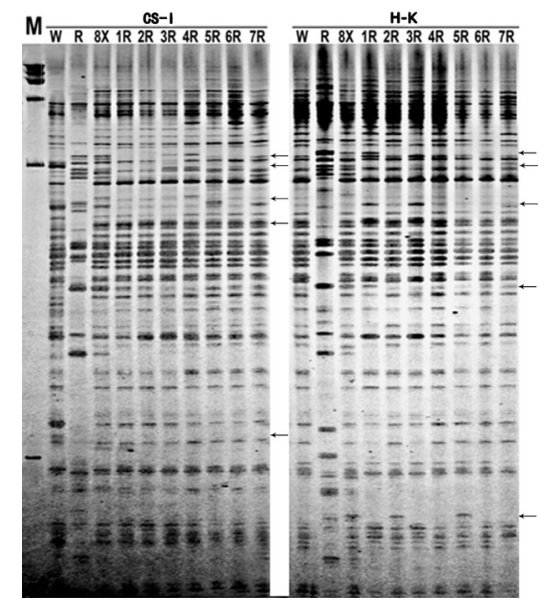

Figure 2. AFLP fingerprints of genomic DNA of wheat-rye additional lines and their parents. Lane $M=$ DNA molecular weight marker; $\mathrm{W}=$ wheat parent $(\mathrm{AABBDD}) ; \mathrm{R}=$ rye parent $(\mathrm{RR}) ; 8 \mathrm{X}=$ triticale $(2 \mathrm{n}=8 \mathrm{x}$, AABBDDRR); $1 \mathrm{R}-7 \mathrm{R}=$ wheat-rye addition lines. 

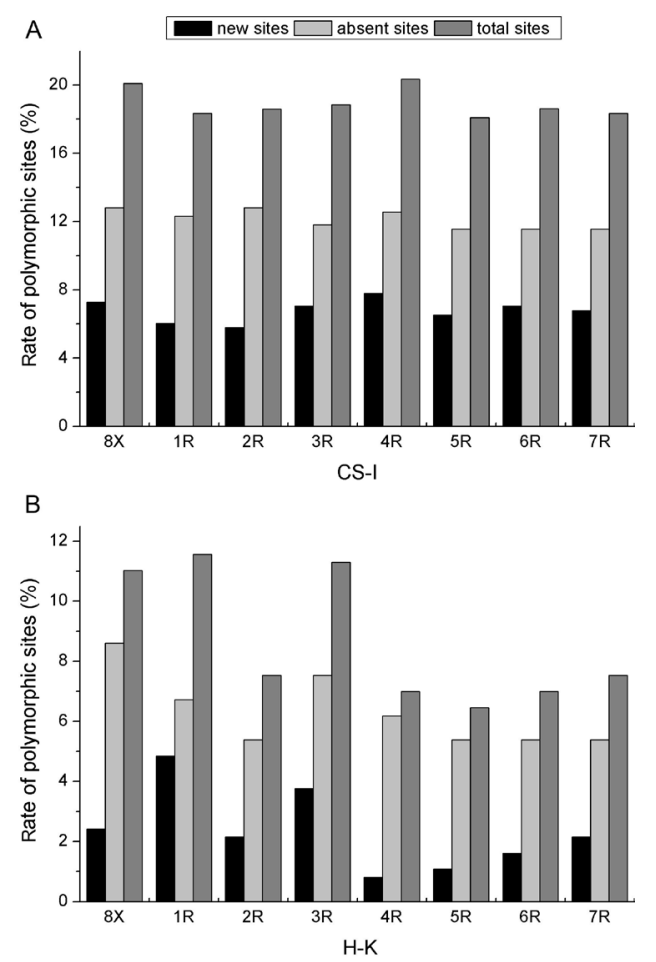

Figure 3. Differences in effect on genetic stability of the wheat recipient genome after alien rye chromosome introduction. A. CS-I; B. H-K. The rate of polymorphic sites compared to the wheat parent in wheat-rye addition lines and triticales was analyzed using AFLP. $(8 \mathrm{X}=$ triticale; $1 \mathrm{R}-7 \mathrm{R}=$ wheat-rye addition lines $)$.

\section{Analysis of addition-associated epigenetic alterations}

Using 11 pairs of EcoRI+HpaII/MspI selective primer combinations in the MSAP analysis, 664 and 750 legible and reproducible bands were obtained in CS-I and H-K, respectively, with the exception of the bands produced by the rye parent (Figure 4). Each band represented a recognition site cleaved by one or both of the isoschizomers. The comparison of the number of methylated sites, including fully methylated and hemi-methylated sites, and the rate of DNA methylation variation between the addition lines and the wheat parent are shown in Table 2 and Figure 5.

In CS-I, we observed that the extent of genomic DNA methylation, both the fully methylated and hemi-methylated level, increased in all addition lines compared to the wheat parent. Furthermore, the hemi-methylated level was higher than fully methylated level in all materials analyzed. In $\mathrm{H}-\mathrm{K}$, the result showed that the extent of genomic DNA methylation in triticale and the six addition lines, except for $5 \mathrm{R}$ addition, was elevated compared to the wheat parent. As shown in Table 2 and Figure 5, the numbers of fully methylated sites for all addition lines were higher than in the wheat parent $(24.67 \%)$, while the numbers of hemi-methylated sites for five additions (1R, 2R, 3R, 4R, and 5R) were lower (37.87\%). Similarly, in CS-I, the number of fully methylated sites $(30.00 \%)$ was higher in triticale, while the number of hemimethylated sites was lower. 


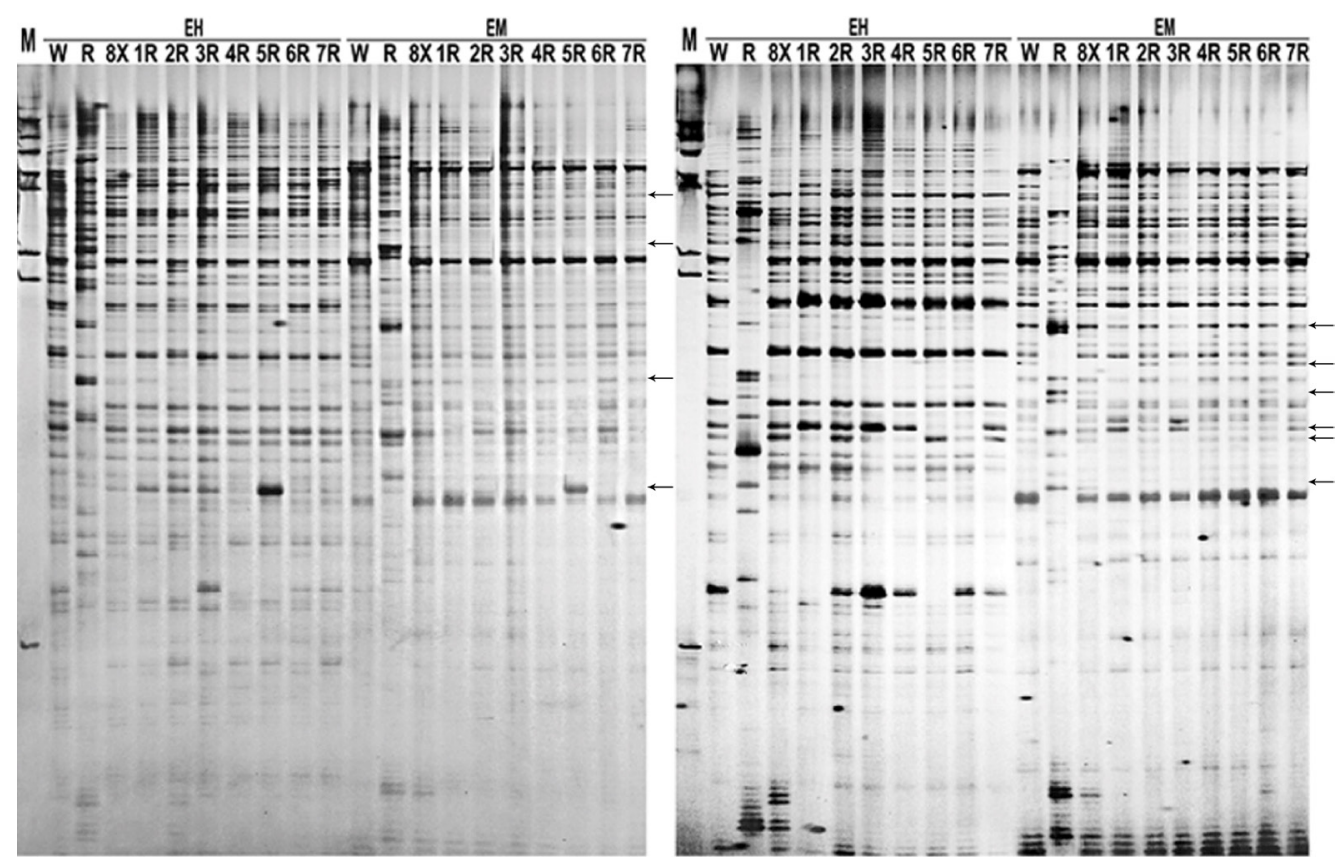

Figure 4. MSAP fingerprints of genomic DNA of the wheat-rye addition lines and their parents and variation of methylation pattern. (Left panel: CS-I; right panel: H-K; lane M: the DNA molecular weight marker; EH: EcoRI+HpaII; EM: EcoRI+MspI).

Table 2. Number of bands amplified by MSAP in the wheat-rye addition lines, triticale and their wheat parent.

\begin{tabular}{|c|c|c|c|c|c|c|c|c|c|c|c|c|c|c|c|c|c|c|}
\hline \multirow{2}{*}{$\begin{array}{l}\text { Primer combinations } \\
\text { CS-I }\end{array}$} & \multicolumn{9}{|c|}{ Fully methylated site } & \multicolumn{9}{|c|}{ Hemi-methylated site } \\
\hline & $\mathrm{W}^{*}$ & $\mathrm{~T}^{*}$ & $\mathrm{IR}$ & $2 \mathrm{R}$ & $3 \mathrm{R}$ & $4 \mathrm{R}$ & $5 \mathrm{R}$ & $6 \mathrm{R}$ & $7 \mathrm{R}$ & $\mathrm{W}^{*}$ & $\mathrm{~T}^{*}$ & $1 \mathrm{R}$ & & $3 \mathrm{R}$ & $4 \mathrm{R}$ & $5 \mathrm{R}$ & $6 \mathrm{R}$ & $7 \mathrm{R}$ \\
\hline E-ACG+H/M-TCT & 5 & 15 & 11 & 12 & 11 & 10 & 8 & 8 & 8 & 13 & 8 & 8 & 10 & 11 & 9 & 10 & 9 & 9 \\
\hline E-ACT+H/M-TCGA & 13 & 19 & 19 & 21 & 20 & 21 & 20 & 20 & 20 & 20 & 21 & 25 & 29 & 29 & 30 & 29 & 29 & 25 \\
\hline E-AGC+H/M-TCA & 10 & 11 & 10 & 12 & 8 & 8 & 9 & 8 & 9 & 13 & 12 & 10 & 11 & 13 & 12 & 15 & 13 & 12 \\
\hline E-AAG+H/M-TCGA & 8 & 12 & 10 & 11 & 11 & 9 & 8 & 8 & 6 & 14 & 9 & 8 & 13 & 13 & 13 & 19 & 18 & 18 \\
\hline E-ACA+H/M-TCGA & 15 & 17 & 19 & 19 & 19 & 18 & 16 & 16 & 16 & 13 & 13 & 13 & 14 & 14 & 15 & 14 & 15 & 13 \\
\hline E-AGC+H/M-TGG & 19 & 20 & 21 & 20 & 19 & 20 & 19 & 20 & 18 & 18 & 21 & 22 & 22 & 22 & 19 & 19 & 22 & 20 \\
\hline E-ACA+H/M-TCCA & 6 & 8 & 8 & 9 & 9 & 10 & 9 & 8 & 10 & 5 & 3 & 2 & 3 & 2 & 3 & 3 & 2 & 3 \\
\hline E-ACG $+\mathrm{H} / \mathrm{M}-\mathrm{TCGA}$ & 10 & 7 & 6 & 3 & 5 & 5 & 8 & 6 & 7 & 2 & 10 & 16 & 11 & 15 & 13 & 20 & 17 & 16 \\
\hline E-AGC+H/M-TCCA & 6 & 5 & 3 & 4 & 5 & 6 & 5 & 5 & 5 & 18 & 21 & 21 & 23 & 23 & 19 & 19 & 22 & 19 \\
\hline E-AAG+ H/M-TGC & 13 & 18 & 13 & 13 & 14 & 14 & 13 & 12 & 12 & 34 & 29 & 32 & 38 & 38 & 40 & 39 & 40 & 39 \\
\hline E-ACG+H/M-TCAA & 17 & 18 & 18 & 18 & 22 & 21 & 19 & 21 & 19 & 21 & 22 & 21 & 23 & 21 & 19 & 21 & 24 & 24 \\
\hline \multirow{2}{*}{ Total (\%) } & 122 & 150 & 138 & 142 & 143 & 142 & 134 & 132 & 130 & 171 & 169 & 178 & 197 & 201 & 192 & 208 & 211 & 198 \\
\hline & 18.37 & 22.59 & 20.78 & 21.39 & 21.54 & 21.39 & 20.18 & 19.88 & 19.58 & 25.75 & 25.45 & 26.81 & 29.67 & 30.27 & 28.92 & 31.33 & 31.78 & 29.82 \\
\hline $\mathrm{H}-\mathrm{K}$ & $\mathrm{W}^{*}$ & $\mathrm{~T}^{*}$ & $1 \mathrm{R}$ & $2 \mathrm{R}$ & $3 \mathrm{R}$ & $4 \mathrm{R}$ & $5 \mathrm{R}$ & $6 \mathrm{R}$ & $7 \mathrm{R}$ & W & $\mathrm{T}$ & $1 \mathrm{R}$ & $2 \mathrm{R}$ & $3 \mathrm{R}$ & $4 \mathrm{R}$ & $5 \mathrm{R}$ & $6 \mathrm{R}$ & $7 \mathrm{R}$ \\
\hline E-ACG+H/M-TCT & 27 & 34 & 29 & 30 & 26 & 26 & 24 & 17 & 19 & 12 & 8 & 10 & 9 & 13 & 13 & 13 & 26 & 17 \\
\hline $\mathrm{E}-\mathrm{ACT}+\mathrm{H} / \mathrm{M}-\mathrm{TCGA}$ & 20 & 23 & 23 & 22 & 22 & 22 & 21 & 21 & 21 & 21 & 23 & 19 & 25 & 23 & 24 & 22 & 23 & 22 \\
\hline E-AAG $+\mathrm{H} / \mathrm{M}-\mathrm{TCGA}$ & 13 & 13 & 11 & 12 & 11 & 10 & 11 & 11 & 11 & 29 & 28 & 30 & 28 & 27 & 24 & 24 & 23 & 27 \\
\hline $\mathrm{E}-\mathrm{ACA}+\mathrm{H} / \mathrm{M}-\mathrm{TCCA}$ & 11 & 12 & 11 & 11 & 11 & 11 & 11 & 11 & 10 & 12 & 13 & 11 & 12 & 14 & 12 & 12 & 12 & 12 \\
\hline E-AGC+H/M-TGG & 19 & 21 & 21 & 21 & 18 & 18 & 19 & 18 & 18 & 20 & 22 & 24 & 23 & 24 & 23 & 22 & 22 & 23 \\
\hline E-ACG $+\mathrm{H} / \mathrm{M}-\mathrm{TCGA}$ & 22 & 24 & 23 & 22 & 23 & 22 & 22 & 22 & 22 & 27 & 31 & 29 & 29 & 27 & 28 & 29 & 27 & 27 \\
\hline E-ACG $+\mathrm{H} / \mathrm{M}-\mathrm{TCAA}$ & 18 & 36 & 25 & 33 & 31 & 23 & 26 & 30 & 29 & 38 & 32 & 32 & 29 & 29 & 33 & 31 & 35 & 35 \\
\hline E-ACA $+\mathrm{H} / \mathrm{M}-\mathrm{TCGA}$ & 10 & 13 & 14 & 13 & 13 & 13 & 13 & 14 & 12 & 25 & 22 & 23 & 21 & 21 & 22 & 22 & 25 & 24 \\
\hline E-AGC+H/M-TCCA & 15 & 14 & 15 & 15 & 16 & 15 & 15 & 15 & 15 & 25 & 31 & 28 & 27 & 28 & 26 & 26 & 26 & 25 \\
\hline E-AGC+H/M-TCA & 16 & 17 & 17 & 16 & 15 & 16 & 15 & 17 & 16 & 34 & 36 & 30 & 33 & 32 & 34 & 34 & 33 & 36 \\
\hline $\mathrm{E}-\mathrm{AAG}+\mathrm{H} / \mathrm{M}-\mathrm{TGC}$ & 14 & 18 & 16 & 14 & 14 & 14 & 14 & 14 & 14 & 42 & 38 & 42 & 40 & 39 & 41 & 40 & 41 & 40 \\
\hline \multirow{2}{*}{ Total (\%) } & 185 & 225 & 205 & 209 & 200 & 190 & 191 & 190 & 187 & 285 & 284 & 278 & 276 & 277 & 280 & 275 & 293 & 288 \\
\hline & 24.67 & 30.00 & 27.33 & 27.87 & 26.67 & 25.33 & 25.47 & 25.33 & 24.93 & 38.00 & 37.87 & 37.07 & 36.80 & 36.93 & 37.33 & 36.67 & 39.07 & 38.40 \\
\hline
\end{tabular}

$* \mathrm{~W}=$ wheat $\mathrm{T}=$ triticale; $1 \mathrm{R}-7 \mathrm{R}=1 \mathrm{R}-7 \mathrm{R}$ addition lines. 

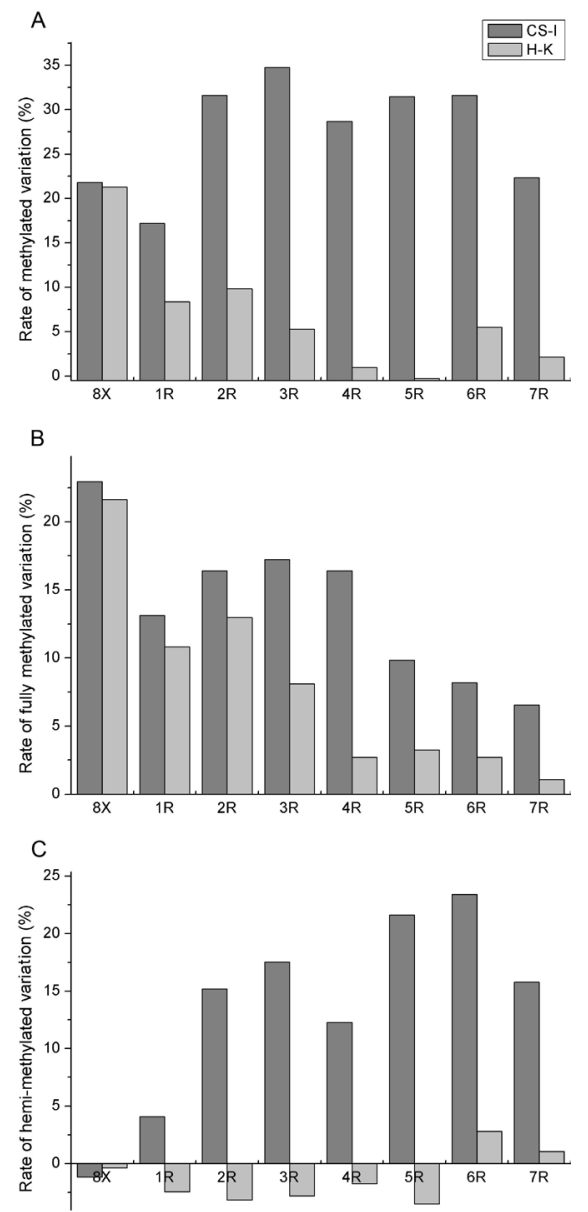

Figure 5. Rate of DNA methylation variation compared to the wheat parent in the wheat recipient genome after alien rye chromosome introduction. A. Methylated; B. fully methylated; C. hemi-methylated variations. The rate was calculated according to the following equation: $r=$ (number of sites $\mathrm{AL} / 8 \mathrm{X}-$ number of sites W) $\times 100 \%$ / number of sites W.

By comparing the MSAP amplified fingerprints between the triticale/addition lines and the wheat parent, polymorphic methylation sites were identified. The methylation pattern "CCGG/GGCC" differed in the wheat parent compared to that in the different addition lines/ triticale. Based on the variation in the "CCGG/GGCC" methylation site, the polymorphisms can be categorized into three types: i) hypermethylation polymorphism sites (PH), in which the extent of cytosine methylation was greater than that in the wheat parent; ii) demethylation polymorphism sites (PD), in which the extent of cytosine methylation was lesser than that in the wheat parent; and iii) other sites (PU), in which the extent of cytosine methylation could not be accurately compared to that in the wheat parent (Table 3). In CS-I, 286 polymorphic methylated fragments were generated in the wheat-rye addition lines and amphidiploid. Among the "CCGG/GGCC" methylation sites, the number of PH, PD, and PU sites were 162 (56.64\%), 86 (30.07\%), and 38 (13.29\%), respectively (Table 3). In H-K, 224 methylated sites 
showed polymorphism among the addition lines, triticale, and the wheat parent. The number of PH, PD, and PU sites were 126 (56.25\%), 44 (19.64\%), and 54 (24.11\%), respectively (Table 3). We also found that hypermethylation is the major response of the wheat genome to rye chromosome addition and triticale. In summary, the MSAP analysis indicated that the existence of alien germplasm, both entire genome and sub-genome, in the wheat genetic background, evoked obvious and diversiform variations in the extent and pattern of the genomic DNA methylation of its recipient.

Table 3. Patterns of cytosine methylation in wheat-rye addition lines and wheat parent.

\begin{tabular}{|c|c|c|c|c|c|c|c|c|}
\hline \multirow[t]{2}{*}{ Polymorphic sites } & \multicolumn{2}{|c|}{$\mathrm{W}^{*}$} & \multicolumn{2}{|c|}{$\mathrm{T}^{*} / \mathrm{AL}^{*}$} & \multicolumn{2}{|c|}{ CS-I } & \multicolumn{2}{|c|}{$\mathrm{H}-\mathrm{K}$} \\
\hline & $\mathrm{EH}$ & EM & $\mathrm{EH}$ & EM & No. & $\%$ & No. & $\%$ \\
\hline \multirow[t]{4}{*}{ Hypermethylation } & - & - & + & - & 86 & \multirow[t]{4}{*}{$162(56.64 \%)$} & 69 & \multirow[t]{4}{*}{$126(56.25 \%)$} \\
\hline & - & - & - & + & 29 & & 35 & \\
\hline & + & + & + & - & 17 & & 5 & \\
\hline & + & + & - & + & 30 & & 17 & \\
\hline \multirow[t]{4}{*}{ Demethylation } & + & - & + & + & 14 & \multirow[t]{4}{*}{$86(30.07 \%)$} & 12 & \multirow[t]{4}{*}{$44(19.64 \%)$} \\
\hline & + & - & - & + & 9 & & 6 & \\
\hline & - & - & + & + & 32 & & 7 & \\
\hline & - & + & + & + & 31 & & 19 & \\
\hline \multirow[t]{2}{*}{ Other } & + & - & - & - & 24 & \multirow[t]{2}{*}{$38(13.29 \%)$} & 48 & \multirow[t]{2}{*}{$54(24.11 \%)$} \\
\hline & - & + & - & - & 14 & & 6 & \\
\hline
\end{tabular}

$* \mathrm{~W}=$ wheat $\mathrm{T}=$ triticale; $\mathrm{AL}=$ addition lines; $+=$ band present; $-=$ band absent.

\section{Sequence analysis of polymorphic fragments}

Polymorphic fragments displaying genomic and epigenomic changes were gel isolated, re-amplified, and sequenced. The BLASTn and BLASTx results revealed that the polymorphic loci consist of protein-coding genes and transposon/retrotransposon-related sequences (Table 4 and Figure 6). Subsequently, 20 polymorphic fragments showing genomic primary structure alterations were analyzed. Among these 20 bands, $13(65 \%)$ sequences

Table 4. Sequence analysis of the polymorphic fragments displaying genomic and epigenomic changes.

\begin{tabular}{|c|c|c|c|c|}
\hline Sequence & Length (bp) & Homologous sequence & Gene locus flanking & E-value \\
\hline PGe-1 & 223 & Oryza sativa Japonica group hypothetical protein (NM001059942) & None & $4.00 \mathrm{E}-38$ \\
\hline PGe-2 & 245 & T. aestivum retrotransposon (DQ537335) & High molecular weight glutelin, protein kinase & $2.00 \mathrm{E}-91$ \\
\hline PGe-3 & 187 & T. aestivum $\mathrm{GA}$ induced protein (EU095332) & None & $2.00 \mathrm{E}-84$ \\
\hline PGe-4 & 156 & T. aestivum $\mathrm{GA}$ induced protein (EU095332) & None & $3.00 \mathrm{E}-41$ \\
\hline PGe-5 & 129 & T. aestivum retrotransposon (AY368673) & High molecular weight glutelin, protein kinase & $3.00 \mathrm{E}-27$ \\
\hline PGe-6 & 201 & T. aestivum retrotransposon (DQ537336) & High molecular weight glutenin subunit & $2.00 \mathrm{E}-64$ \\
\hline PGa-7 & 201 & Oryza sativa Japonica group transposon (AP005683) & BRIl-KD interacting protein 120 & $1.00 \mathrm{E}-15$ \\
\hline PGa-8 & 282 & T. aestivum retrotransposon (EU835980) & Cell division AAA ATPase family protein & $1.00 \mathrm{E}-56$ \\
\hline PGa-9 & 199 & T. monococcum Caspar ORF-2 transposase (AY146588) & Caspar transposase & $7.00 \mathrm{E}-77$ \\
\hline PGa-10 & 393 & T. aestivum transposon (AM932682) & RelicGene-TAB63B7-1 & $9.00 \mathrm{E}-124$ \\
\hline PGa-11 & 279 & Zea mays subsp mays NADH intron of dehydrogenase gene (DQ490951) & ATPase subunit 8 & $4.00 \mathrm{E}-50$ \\
\hline PGa-12 & 163 & T. aestivum transposon (AM932684) & Transposon & $6.00 \mathrm{E}-51$ \\
\hline PGa-13 & 238 & T. turgidum retrotransposon (AY494981) & Glutelin & $6.00 \mathrm{E}-60$ \\
\hline PGa-14 & 307 & T. monococcum transposon (AF459639) & Cleavage promoting factor & $3.00 \mathrm{E}-64$ \\
\hline PGa-15 & 271 & T. aestivum transposon (DQ537335) & $\mathrm{X}$-type HMW glutenin & $1.00 \mathrm{E}-88$ \\
\hline PGa-16 & 463 & Aegilops ventricosa $\mathrm{NBS}-\mathrm{LRR}$ resistance-related hypothetical protein (AF158635) & Coding region of this protein & $5.00 \mathrm{E}-109$ \\
\hline PGa-17 & 166 & T. aestivum retrotransposon (AM932682) & Retrotransposon & $1.00 \mathrm{E}-15$ \\
\hline PGa-18 & 382 & T. aestivum retrotransposon (AB298185) & Gene of protein P450 & $2.00 \mathrm{E}-74$ \\
\hline PGa-19 & 274 & T. turgidum retrotransposon (AY368673) & HMW-glutenin Bx subunit & $4.00 \mathrm{E}-113$ \\
\hline PGa-20 & 202 & Oryza sativa Japonica group protein (AK119256) & cDNA cloning of whole gene & $1.00 \mathrm{E}-09$ \\
\hline PE-1 & 473 & T. aestivum retrotransposon (AY368673) & HMW-glutenin Bx subunit & $3.00 \mathrm{E}-155$ \\
\hline PE-2 & 495 & T. aestivum transposon (AM932682) & Transposon & $7.00 \mathrm{E}-114$ \\
\hline PE-3 & 363 & Hordeum vulgare subsp vulgare protein (AK249655) & cDNA cloning of whole gene & $8.00 \mathrm{E}-105$ \\
\hline PE-4 & 300 & T. turgidum transposon (EU835198) & Wheat kinase-START domain protein & $4.00 \mathrm{E}-133$ \\
\hline PE-5 & 272 & T. aestivum retrotransposon (AB298185) & Gene of protein $\mathrm{P} 450$ & $9.00 \mathrm{E}-109$ \\
\hline PE-6 & 551 & T. monococcum transposon (AF459639) & Hypothetical threonine kinase & $3.00 \mathrm{E}-24$ \\
\hline PE-7 & 248 & Oryza sativa drought resistance-related regulatory protein (AF366563) & Coding region of this protein & $4.00 \mathrm{E}-68$ \\
\hline PE-8 & 339 & Triticum aestivum protein (AK332042) & cDNA cloning of whole gene & $4.00 \mathrm{E}-07$ \\
\hline
\end{tabular}


were related to transposable elements, implicating transposable elements as main targets for genomic structure alterations in the addition lines. Further analysis revealed that $50 \%$ of the sequences detected by EST-SSR showed significant similarities to protein-coding sequences, while only $29 \%$ of the sequences detected by AFLP were located in a protein-coding region. Eight MSAP fragments that displayed methylation alterations were analyzed. Five (62.5\%) of the eight bands were found to be related to transposable elements and the other three (37.5\%) showed significant similarities to sequences encoding proteins (Figure 6).
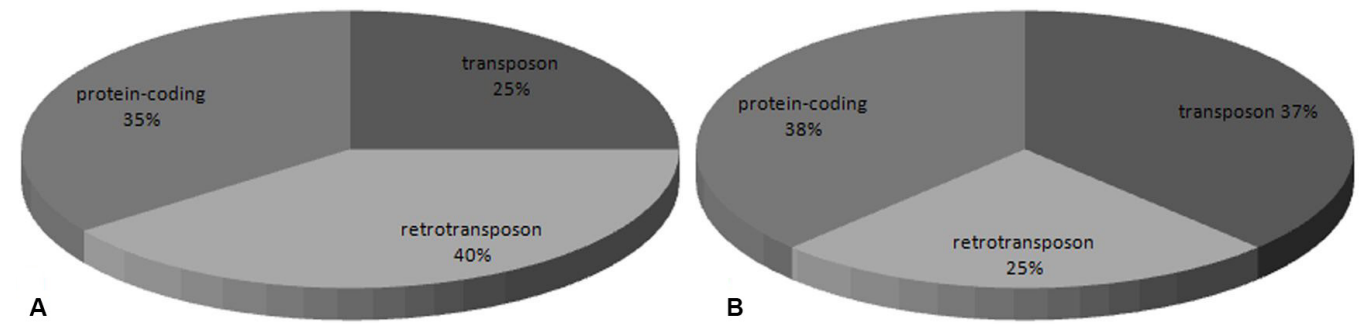

Figure 6. Different distribution regions of the polymorphic fragments analyzed. A. Polymorphic fragments obtained by genomic changes. B. Polymorphic fragments obtained by epigenomic changes.

\section{DISCUSSION}

Wide genetic variations in genomic structure and remodeling of DNA methylation patterns in recipient species could be induced by the introduction of foreign germplasms, allopolyploids, or hybrids (Shaked et al., 2001; Ma et al., 2004; Szakács and Molnár-Láng, 2010; Liu et al., 2014). Ma et al. (2004) discovered extensive polyploidization-induced genome variation in triticale (x Triticosecale Wittmack), using both AFLP and RFLP analyses. They also investigated genome variation in wheat-rye addition lines and found that the observed genome variation in these lines was similar to that in triticale. Since the genome compositions of the addition lines were much simpler than the corresponding triticales', the wheat-rye addition lines could be used to study the genome evolution of polyploid triticale (Ma et al., 2004). Another study investigated the genetic stability of wheat-rye ("Chinese Spring" x "Imperial") disomic addition lines, by using the Feulgen method and fluorescent in situ hybridization (Szakács and Molnár-Láng, 2010). Subsequent research on wheat-rye 2R and $5 \mathrm{R}$ indicated that wheat-rye monosomic addition lines could induce different and drastic genetic/epigenetic variations, and these variations might not be caused by introgression of rye chromatins into wheat (Fu et al., 2013).

In the present study, the AFLP, EST-SSR, and MSAP analyses suggested that the existence of alien germplasm evoked obvious and diversiform variation of genomic primary structure, and it also caused alterations in the extent and pattern of the recipient genomic DNA methylation. In genomic variations, the frequency of parental band loss was much higher than the frequency of gaining novel bands. This suggests that deletion might be a major force causing genomic structural variation in wheat-rye addition lines. In epigenetic variations, the hemi-methylated level was much higher than fully methylated level in all analyzed materials and hyper-methylation was the major response of the wheat genome to rye chromosome addition. Interestingly, polyploidization-induced genetic and epigenetic variation in triticale 
showed high similarity to that of the addition lines. This result was consistent with that of Ma et al. (2004).

Moreover, the loci underwent diverse genetic changes or methylation alterations, comprised of both transposon/retrotransposon-related sequences and protein-coding genes, where the former was the most common (Figure 6). Previous studies have demonstrated that the methylation modification patterns of a set of loci, including repetitive sequences, transposable elements, promoter sequences, and protein-coding regions, were changed in the process of wide hybridization. In addition, transposable elements, and other repetitive sequences, are the main targets for methylation mutations. Meanwhile, these variations could affect a series of plant phenotypic characteristics, such as flowering time, fertility, and morphology (Cheng et al., 2006; Dong et al., 2006; Cantu et al., 2010). In our study, sequence PM-24 identified from polymorphic methylated fragments, showed high similarities to a drought resistance-related regulatory gene cloned from rice. This indicates that variation in methylation may influence gene expression and agronomy traits in a given addition line. Previous studies have also demonstrated that alien DNA introgression into the plant genome could induce extensive alterations in DNA methylation without causing obvious variations in the genomic primary structure in the same introgression and translocation lines separated at an advanced generation (Dong et al., 2006). It was presumed that in the process of "addition, fragmentation and integration", the genetic variations evoked in addition lines, an early hybrid generation with unstable genetic background, would disappear in those highly stabilized introgression lines, while the epigenetic variations evoked in early generations might be stably inherited to the progeny.

\section{Conflicts of interest}

The authors declare no conflict of interest.

\section{ACKNOWLEDGMENTS}

Research supported by the National Natural Science Foundation of China (\#31271420 and \#31371682), the National Transgenic Major Project (\#2014ZX0801003B-002), and the Fundamental Research Funds for the Central Universities (\#ZYGX2013J099). The authors are most grateful to Xiaonan Zhao and Peigao Luo for their experimental assistance.

\section{REFERENCES}

Alkhimova AG, Heslop-Harrison JS, Shchapova AI and Vershinin AV (1999). Rye chromosome variability in wheat-rye addition and substitution lines. Chromosome Res. 7: 205-212. http://dx.doi.org/10.1023/A:1009299300018

Bento M, Gustafson P, Viegas W and Silva M (2010). Genome merger: from sequence rearrangements in triticale to their elimination in wheat-rye addition lines. Theor. Appl. Genet. 121: 489-497. http://dx.doi.org/10.1007/s00122-010-1325-6

Brar DS and Khush GS (1997). Alien introgression in rice. Plant Mol. Biol. 35: 35-47. http://dx.doi. org/10.1023/A:1005825519998

Cantu D, Vanzetti LS, Sumner A, Dubcovsky M, et al. (2010). Small RNAs, DNA methylation and transposable elements in wheat. BMC Genomics 11: 408. http://dx.doi.org/10.1186/1471-2164-11-408

Cheng C, Daigen M and Hirochika H (2006). Epigenetic regulation of the rice retrotransposon Tos17. Mol. Genet. Genomics 276: 378-390. http://dx.doi.org/10.1007/s00438-006-0141-9

Chevre AM, Eber F, This P, Barret P, et al. (1996). Characterization of Brassica nigra chromosomes and of blackleg resistance in B. napus-B. nigra addition lines. Plant Breed. 115: 113-118. http://dx.doi.org/10.1111/j.1439-0523.1996.tb00884.x 
Dong ZY, Wang YM, Zhang ZJ, Shen Y, et al. (2006). Extent and pattern of DNA methylation alteration in rice lines derived from introgressive hybridization of rice and Zizania latifolia Griseb. Theor. Appl. Genet. 113: 196-205. http://dx.doi.org/10.1007/s00122-006-0286-2

Friebe B, Jiang J, Raupp WJ, McIntosh RA, et al. (1996). Characterization of wheat-alien translocations conferring resistance to diseases and pests. Euphytica 91: 59-87. http://dx.doi.org/10.1007/BF00035277

Fu S, Sun C, Yang M, Fei Y, et al. (2013). Genetic and epigenetic variations induced by wheat-rye 2R and 5R monosomic addition lines. PLoS One 8: e54057. http://dx.doi.org/10.1371/journal.pone.0054057

Gill BS, Friebe BR and White FF (2011). Alien introgressions represent a rich source of genes for crop improvement. Proc. Natl. Acad. Sci. USA 108: 7657-7658. http://dx.doi.org/10.1073/pnas.1104845108

Jauhar PP and Peterson TS (2013). Synthesis and characterization of advanced durum wheat hybrids and addition lines with thinopyrum chromosomes. J. Hered. 104: 428-436. http://dx.doi.org/10.1093/jhered/ess143

Kang H, Wang Y, Fedak G, Cao W, et al. (2011). Introgression of chromosome 3Ns from Psathyrostachys huashanica into wheat specifying resistance to stripe rust. PLoS One 6: e21802. http://dx.doi.org/10.1371/journal.pone.0021802

Liu TJ, Sun LF, Shan XH, Wu Y, et al. (2014). Analysis of DNA methylation patterns and levels in maize hybrids and their parents. Genet. Mol. Res. 13: 8458-8468. http://dx.doi.org/10.4238/2014.October.20.22

Liu W, Rouse M, Friebe B, Jin Y, et al. (2011). Discovery and molecular mapping of a new gene conferring resistance to stem rust, Sr53, derived from Aegilops geniculata and characterization of spontaneous translocation stocks with reduced alien chromatin. Chromosome Res. 19: 669-682. http://dx.doi.org/10.1007/s10577-011-9226-3

Ma XF and Gustafson JP (2006). Timing and rate of genome variation in triticale following allopolyploidization. Genome 49: 950-958. http://dx.doi.org/10.1139/G06-078

Ma XF, Fang P and Gustafson JP (2004). Polyploidization-induced genome variation in triticale. Genome 47: 839-848. http://dx.doi.org/10.1139/g04-051

Multani DS, Khush GS, delos Reyes BG and Brar DS (2003). Alien genes introgression and development of monosomic alien addition lines from Oryza latifolia Desv. to rice, Oryza sativa L. Theor. Appl. Genet. 107: 395-405. http:// dx.doi.org/10.1007/s00122-003-1214-3

Qi L, Friebe B, Zhang P and Gill BS (2007). Homoeologous recombination, chromosome engineering and crop improvement. Chromosome Res. 15: 3-19. http://dx.doi.org/10.1007/s10577-006-1108-8

Reamon-Ramos SM and Wricke G (1992). A full set of monosomic addition lines in Beta vulgaris from Beta webbiana: morphology and isozyme markers. Theor. Appl. Genet. 84:411-418.http://link.springer.com/article/10.1007/BF00229501

Ren TH, Chen F, Zhang HQ, Yan BJ, et al. (2011). Application of 1RS.1BL translocation in the breeding of "Chuangnong" series wheat cultivars. J. Triticeae Crops 31: 430-436.

Ren Z and Zhang H (1997). Induction of small-segment-translocation between wheat and rye chromosomes. Sci. China C Life Sci. 40: 323-331. http://dx.doi.org/10.1007/BF02879094

Ren ZL, Lelley T and Röbbelen G (1990). The use of monosomic rye addition lines for transferring rye chromatin into bread wheat. Plant Breed. 105: 265-270. http://dx.doi.org/10.1111/j.1439-0523.1990.tb01284.x

Shaked H, Kashkush K, Ozkan H, Feldman M, et al. (2001). Sequence elimination and cytosine methylation are rapid and reproducible responses of the genome to wide hybridization and allopolyploidy in wheat. Plant Cell 13: 1749-1759. http://dx.doi.org/10.1105/tpc.13.8.1749

Szakács E and Molnár-Láng M (2010). Molecular cytogenetic evaluation of chromosome instability in Triticum aestivumSecale cereale disomic addition lines. J. Appl. Genet. 51: 149-152. http://dx.doi.org/10.1007/BF03195723

Tan GX (2008). Monosomic alien addition lines: a new tool for studying and using plant genomics. Yi Chuan 30: 35-45. http://dx.doi.org/10.3724/SP.J.1005.2008.00035

Tang ZX, Fu SL, Ren ZL, Zhang HQ, et al. (2009). Characterization of three wheat cultivars possessing new 1BL.1RS wheat-rye translocations. Plant Breed. 128: 524-527. http://dx.doi.org/10.1111/j.1439-0523.2008.01598.x

van Heusden AW, Shigyo M, Tashiro Y, Vrielink-van Ginkel R, et al. (2000). AFLP linkage group assignment to the chromosomes of Allium cepa L. via monosomic addition lines. Theor. Appl. Genet. 100: 480-486. http://dx.doi. org/10.1007/s001220050062

Vos P, Hogers R, Bleeker M, Reijans M, et al. (1995). AFLP: a new technique for DNA fingerprinting. Nucleic Acids Res. 23: 4407-4414. http://dx.doi.org/10.1093/nar/23.21.4407

Zhang Y, Liu ZH, Liu C, Yang ZJ, et al. (2008). Analysis of DNA methylation variation in wheat genetic background after alien chromatin introduction based on methylation-sensitive amplification polymorphism. Chin. Sci. Bull. 53: 58-69. http://dx.doi.org/10.1007/s11434-008-0049-3

Zhou JP, Yao CH, Yang EN, Yin MQ, et al. (2014). Characterization of a new wheat-Aegilops biuncialis addition line conferring quality-associated HMW glutenin subunits. Genet. Mol. Res. 13: 660-669. http://dx.doi.org/10.4238/2014. $\underline{\text { January. } 28.11}$ 


\section{Supplementary material}

S1 Table. Sequences of AFLP and MSAP adapters and primers used in this study.

S2 Table. Polymorphic amplified sites in two set of addition lines analyzed by AFLP. 